\title{
Long-Term Complications of COVID-19 Infection in Adolescents and Children
}

\author{
Keerthi Thallapureddy ${ }^{1} \cdot$ Khyathi Thallapureddy $^{2} \cdot$ Erika Zerda $^{1} \cdot$ Neeraj Suresh $^{3} \cdot$ Deepak Kamat $^{1}$. \\ Karthik Rajasekaran ${ }^{3} \cdot$ Alvaro Moreira $^{1}$
}

Accepted: 14 December 2021 / Published online: 1 February 2022

(c) The Author(s), under exclusive licence to Springer Science+Business Media, LLC, part of Springer Nature 2022

\begin{abstract}
Purpose of Review Compared to adults, post-COVID-19 symptoms are uncommon and have not been thoroughly evaluated in children. This review summarizes the literature in terms of persistent symptoms in children and adolescents after SARSCoV-2 infection.

Recent Findings Children were less likely to develop long COVID when compared to adults. Older children (e.g., adolescents) and those who had symptomatic COVID-19 had a higher probability for long COVID.

Summary Families and health care providers need to be aware of a new constellation of long COVID symptoms in the pediatric population. More evidence and time are needed to better understand the potential effects of long COVID-19 in children and adolescents. In comparison to adults, children are less likely to have persistent COVID-19 symptoms.
\end{abstract}

Keywords Long COVID · COVID-19 · SARS-CoV-2 $\cdot$ Post-acute COVID-19

\section{Introduction}

Severe acute respiratory syndrome coronavirus 2 (SARS$\mathrm{CoV}-2$ ) was identified as a novel human pathogen in December 2019 and has since led to a worldwide pandemic that has threatened human health and public safety [1]. To date, approximately $257 \mathrm{M}$ worldwide cases of SARS-CoV-2 have been detected, yielding a total of $5.1 \mathrm{M}$ deaths. Common symptoms of SARS-CoV-2 infection, commonly referred to as coronavirus disease 2019 (COVID-19), include shortness

This article is part of the Topical Collection on Critical Care

Alvaro Moreira

moreiraa@uthscsa.edu

Keerthi Thallapureddy

kthallapureddy@mail.umkc.edu

Khyathi Thallapureddy

thallapuredd@livemail.uthscsa.edu

Erika Zerda

zerdae@uthscsa.edu

Neeraj Suresh

neeraj.suresh@pennmedicine.upenn.edu

Deepak Kamat

kamatd@uthscsa.edu of breath, fever, cough, sore throat, malaise, myalgias, anorexia, nausea, diarrhea, anosmia, and ageusia [2]. COVID-19 cases in children and adolescents were initially identified as early as January 2020 , but the incidence and severity of the condition are much lower when compared to adults [2]. Up to $20 \%$ of children will not manifest acute COVID-19 symptoms, and symptomatic cases are typically mild, do not require hospital admissions, and rarely fatal [2]. Recently, however, there has been an emergence of children and adolescents presenting with long-term symptoms after SARSCoV-2 infection [3].

Karthik Rajasekaran

karthik.rajasekaran@pennmedicine.upenn.edu

1 Department of Pediatrics, University of Texas HealthSan Antonio, 7703 Floyd Curl Drive, San Antonio, TX 78229-3900, USA

2 University of Missouri-Kansas City School of Medicine, 2411 Holmes Street, Kansas City, MO 64108, USA

3 Department of Otorhinolaryngology, University of Pennsylvania, 3400 Civic Center Blvd, Philadelphia, PA 19104, USA 
Persistent symptoms after COVID-19 have multiple names including "post-COVID conditions," "long-COVID," "long-haul COVID," "post-acute COVID-19," "long-term effects of COVID," and "chronic COVID." For simplicity, this review will be utilizing the term "long COVID." According to the Centers for Disease Control and Prevention (CDC), long COVID has been defined as new, returning, or ongoing symptoms that develop during or after a SARSCoV-2 infection that continue for four or more weeks [4]. The number of symptoms associated with long COVID is vast and includes fatigue, muscle and joint pain, headache, insomnia, respiratory problems, heart palpitations, gastrointestinal problems, nausea, dizziness, seizures, hallucinations, and testicular pain (Table 1). Currently, the literature reporting long COVID has focused on the adult population $[3,5]$.

Among the first studies describing pediatric long COVID was derived from investigators from Gemelli University Hospital in Rome, Italy. According to Buonsesno et al., more than half of the children in the sample of 129 children had at least one symptom lasting more than 120 days [6••]. Herein, we highlight the manifestations of long COVID in the pediatric and adolescent population across several organ systems.

\section{Acute COVID Manifestations}

Prior to discussing long COVID symptoms, we will provide a brief overview of the presentation of SARS-CoV-2 infection in children. A recent review article by Galindo et al. cited that children with COVID-19 typically manifest with fever, and upper respiratory symptoms with/without gastrointestinal symptoms [7]. Likewise, the symptomatic profile of fever, cough, diarrhea, vomiting, rhinorrhea, and headache was also portrayed in the sentinel review by Castagnoli and colleagues $[8 \bullet \bullet]$. In a previous paper, we also describe the classic findings of children diagnosed with COVID-19 [9]. Figure 1 depicts acute symptoms of SARS-CoV-2 infection in more than 7000 children.

\section{Long COVID Manifestations}

\section{General Symptoms}

In a prospective study of school-aged children from the UK, investigators sought to capture illness duration and symptom profiles after SARS-CoV-2 infection [10••]. Seventyseven of 1734 COVID-19-positive children had symptoms that lasted at least 28 days. At a rate of $84.4 \%$, fatigue was the most reported symptom, followed by headache $(77.9 \%$, $n=60)$. Twenty-five of 1379 children had symptoms that lasted $>56$ days; headache occurred in 20 children $(80 \%)$.
Likewise, a follow-up study of 518 Russian children revealed that fatigue $(10.6 \%)$ and sleep disturbance $(7.2 \%)$

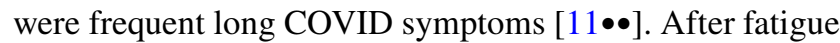
and insomnia, an investigation of long COVID symptoms in Italian children revealed that lack of concentration and weight loss took place in $10.1 \%$ and $7.7 \%$ of individuals, respectively $[6 \bullet \bullet]$.

\section{Psychiatric}

In a study by Zhang and colleagues, the psychological impact of COVID-19 on adolescents who were in continuous treatment for major depressive disorder (MDD) was compared to adolescents with MDD [12]. Using the Diagnostic and Statistical Manual of Mental Disorders IV diagnosis of post-traumatic disorder (PTSD), the investigators found that a higher proportion of adolescents with MDD had increased arousal, avoidance, and flashbacks after the start of the pandemic. Moreover, junior high school students were more likely to exhibit avoidance, while high schoolers experience more intrusive symptoms. In a meta-analysis of 80,879 children, the pooled prevalence of depression and anxiety symptoms during COVID-19 has doubled compared to prepandemic estimates [13]. These findings are consistent with previous studies that have shown that compared to adults, children and adolescents are at higher risk for depression, anxiety, and PTSD after natural disasters [14].

\section{Otolaryngologic}

Patterning the adult population, anosmia has been described as an otolaryngologic manifestation of pediatric COVID $[15,16]$. The previously stated investigation by Molteni and colleagues described anosmia as the second most common symptom (77.9\%) during the entire illness of children with long COVID. While headache, fatigue, and sore throat presented earlier in the disease, anosmia was a later finding in

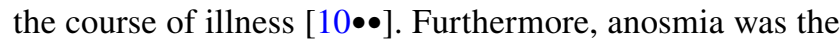
most common symptom $(84.0 \%)$ in a subgroup of children who had long COVID for more than 56 days $(n=25)$.

Changes to smell was an initial presenting symptom of COVID-19 in $14 \%$ of children [11••]. This symptom remained for more than one month, and in some cases more than 5 months, in 22 of 467 children (4.7\%). Dizziness as a long COVID symptom was less common at rate of $2.1 \%$. Problems with balance or fainting were rare to none.

Dysphagia and dysphonia have also been described as a long COVID symptom in children. In a retrospective cohort study of 50 pediatric patients with multisystem inflammation after COVID-19, nine patients required specialist assessment for dysphonia and/or dysphagia (one patient had dysphagia alone, three patients had dysphagia and dysphonia, and five patients had dysphonia alone) [17]. Management 
Table 1 Across pediatric cases

\begin{tabular}{|c|c|c|c|c|c|c|}
\hline First author & Country & Date & Patients $(N)$ & Age (years) & Male $N(\%)$ & Long COVID clinical symptoms \\
\hline Ludvigsson, JF & Sweden & Dec 2020 & 5 & 12 (median) & $1(20 \%)$ & $\begin{array}{l}\text { Fatigue, dyspnea, palpitations, } \\
\text { chest pain, headache, con- } \\
\text { centration difficulties, muscle } \\
\text { pain/weakness, dizziness, } \\
\text { sore throat, abdominal pain, } \\
\text { memory loss, depression, skin } \\
\text { rash, remitting fever, insomnia, } \\
\text { joint pain, anorexia, n/v/d, } \\
\text { anosmia, ageusia, chronic } \\
\text { cough, numbness }\end{array}$ \\
\hline Buonsenso, D & Italy & Jul 2021 & 129 & $11 \pm 4.4$ (mean) & $67(51.9 \%)$ & $\begin{array}{l}\text { Insomnia, respiratory distress, } \\
\text { chest pain/tightness, nasal } \\
\text { congestion, fatigue, muscle/ } \\
\text { joint pain, concentration } \\
\text { difficulties, headache, weight } \\
\text { loss, skin rash, constipation, } \\
\text { persistent cough, altered smell/ } \\
\text { taste, palpitations, abdominal } \\
\text { pain, diarrhea, menstrual } \\
\text { irregularities }\end{array}$ \\
\hline Molteni, E & UK & Aug 2021 & 1734 & $\begin{array}{l}5-11(n=588) \\
12-17(n=1146)\end{array}$ & $\begin{array}{l}5-11(48.8 \%) \\
12-17(50.3 \%)\end{array}$ & $\begin{array}{l}\text { Blisters, red welts, eye soreness, } \\
\text { dizziness and light-head- } \\
\text { edness, anosmia, persistent } \\
\text { cough, fever, diarrhea, confu- } \\
\text { sion, hoarse voice, headache, } \\
\text { myalgias, loss of appetite, } \\
\text { dyspnea, sore throat, chest } \\
\text { pain, abdominal pain, fatigue }\end{array}$ \\
\hline Osmanov, I & Russia & Jul 2021 & 518 & 10.4 (median) & $248(47.9 \%)$ & $\begin{array}{l}\text { Fatigue, nasal congestion/rhi- } \\
\text { norrhea, insomnia, disturbed } \\
\text { smell, headache, disturbed } \\
\text { taste, hyperhidrosis, persis- } \\
\text { tent cough, hypersomnia, } \\
\text { poor appetite, rash, diarrhea, } \\
\text { abdominal pain, hair loss, } \\
\text { dizziness, joint pain/swelling, } \\
\text { heart variability, constipation, } \\
\text { anosmia, chest tightness/pain, } \\
\text { nausea, palpitations, myalgia, } \\
\text { imbalance, urinary issues, } \\
\text { vomiting, confusion, pain on } \\
\text { breathing, difficulty moving, } \\
\text { tremors, bleeding changes in } \\
\text { menstruation, loss of tastes, } \\
\text { pins and needles, problems } \\
\text { swallowing, bilateral conjunc- } \\
\text { tivitis, rash on toes, difficulty } \\
\text { speaking }\end{array}$ \\
\hline Zhang, $\mathrm{H}$ & China & Aug 2021 & 90 & 15 (median) & $18(20.0 \%)$ & $\begin{array}{l}\text { Increased arousal, decreased } \\
\text { intrusion and avoidance, } \\
\text { higher CRIES-13 scores }\end{array}$ \\
\hline Radtke, $\mathrm{T}$ & Switzerland & July 2021 & 109 & $\begin{array}{l}6-11(66) \\
12-16(43)\end{array}$ & $51(46.8 \%)$ & $\begin{array}{l}\text { Tiredness, difficulty concentrat- } \\
\text { ing, increased need for sleep, } \\
\text { congested/runny nose, stomach } \\
\text { ache, chest tightness, cough }\end{array}$ \\
\hline
\end{tabular}


Table 1 (continued)

\begin{tabular}{|c|c|c|c|c|c|c|}
\hline First author & Country & Date & Patients $(N)$ & Age (years) & Male $N(\%)$ & Long COVID clinical symptoms \\
\hline Lindan, CE & $\begin{array}{l}\text { France, UK, USA, Brazil, } \\
\text { Argentina, India, Peru, Saudi } \\
\text { Arabia }\end{array}$ & Mar 2021 & 18 & 8.5 (median) & $11(58 \%)$ & $\begin{array}{l}\text { Encephalopathy, gait impair- } \\
\text { ment, headache, neck pain, } \\
\text { cerebellar ataxia, muscle } \\
\text { weakness, stupor, pyramidal } \\
\text { signs, visual hallucinations, } \\
\text { meningismus, AMS, } 4 \text { limb } \\
\text { motor/bladder dysfunction, } \\
\text { ophthalmoplegia, flaccid } \\
\text { paralysis, ptosis, hypotonia, } \\
\text { seizures }\end{array}$ \\
\hline Halfpenny, R & UK & Jun 2021 & 50 & 10 (median) & $33(66 \%)$ & $\begin{array}{l}\text { Dysphagia, dysphonia, hoarse- } \\
\text { ness }\end{array}$ \\
\hline
\end{tabular}

Fig. 1 A summary of the of the long-term COVID-19 symptoms in children and adolescents

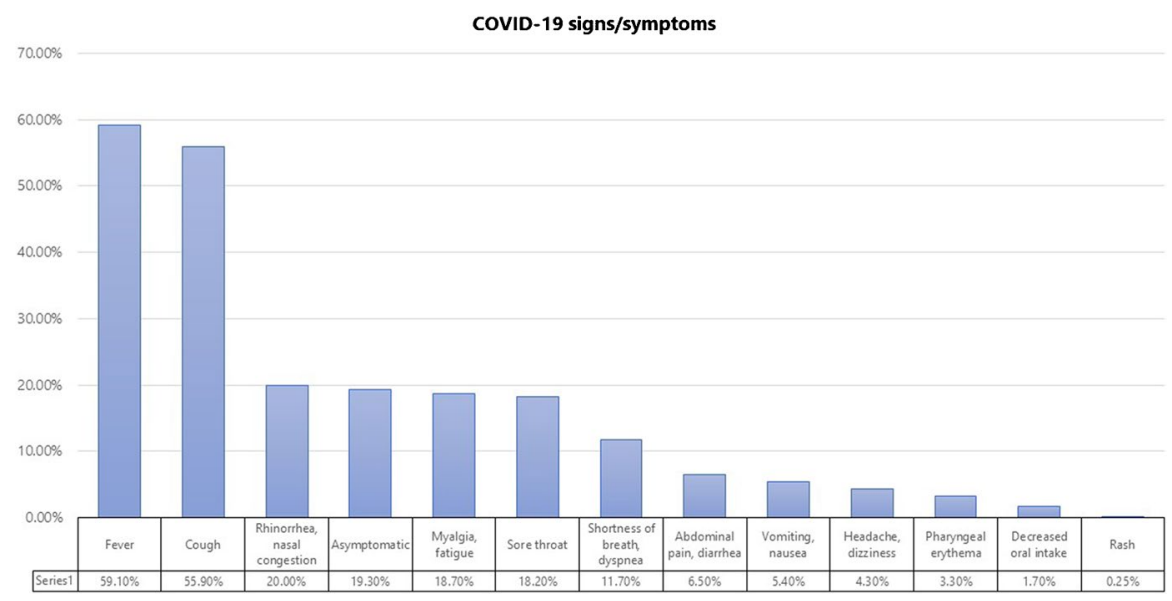

of the patients' dysphonia was conservative including voice therapy and exercises; only one child required surgical intervention. Six out of the eight patients with dysphonia had complete resolution by six months. Dysphagia was seen in four patients requiring total parenteral nutrition or nasogastric tube feeds. All four children had resolution of symptoms between 28 and 127 days. Currently, it is unknown whether these symptoms were secondary to intubation, the post-inflammatory condition, or both.

\section{Neurologic}

In an international, multicenter collaborative study, Lindan et al. sought to evaluate the neuroimaging and neurologic manifestations in a cohort of COVID-19-infected children, including children both with acute COVID-19 and long COVID [18•]. Most cases led to resolution of symptoms, but some long-term complications included dysfunctional/ delayed bladder emptying, emotional lability, mild residual peripheral neuropathy, or facial weakness and ptosis. A similar report by Singer et al. investigated the neurologic manifestations of nine children who had SARS-CoV-2 infection [19]. Common diagnoses in children with long
COVID included acute disseminated encephalomyelitis, encephalitis, and Guillain Barre Syndrome (GBS). While most of these children had full recovery, a small fraction continued to manifest neurologic symptoms including spastic/flaccid quadriparesis, global hyperreflexia, and incomplete sphincter. Another case report by Frank et al. described a fifteen-year-old male patient with COVID-19 diagnosed with GBS with persistent weakness in the upper and lower extremities, currently undergoing motor physiotherapy [20].

Echoing the above studies, a prospective cohort of 52 children and adolescents from the UK described the spectrum of neurological and psychiatric manifestations linked to COVID-19. Thirty-three percent of children had some degree of neurologic disability 1-6 months after COVID-19 hospital discharge. Parents and clinicians should be aware of these potential devastating neurologic symptoms in children after COVID-19 and it is recommended that they expedite formal neurologic evaluation and multidisciplinary management to improve outcomes. Furthermore, children presented to the emergency department or primary care providers with new onset neurologic symptoms should undergo SARSCoV-2 testing. 


\section{Cardiovascular}

Radtke and colleagues assessed long-term symptoms after SARS-CoV-2 infection in schoolchildren from Switzerland [21•]. Of 1355 children, $8.0 \%(n=109)$ had a seropositive test for SARS-CoV-2 infection. Symptoms lasting more than a month were low (9\%) and lasting more than 12 weeks occurred in only 4 individuals. Chest tightness was a long COVID-19 symptom that was reported in 1 child and persisted for more than three months [21].

In another study, clinicians surveyed 518 children and their families regarding symptoms that persisted months after COVID-19 infection [11••]. Palpitations and variations in heart rate were reported in $7 / 472(1.5 \%)$ and $10 / 494$ (2.0\%), respectively. Similarly, in a case series of 129 children, palpitations, chest pain, or chest tightness was described in 3.1 to $6.2 \%$ of the cohort after the diagnosis of COVID-19 [22]. Although cardiovascular symptoms can be seen in children after COVID-19, they seem to be a rare phenomenon.

\section{Pulmonary}

In an Australian study of 171 children, $12(7.0 \%)$ had a long COVID symptom (PMID: $33,891,880)$. Specific to the respiratory system, 6 children (50\%) had a post-viral cough that ranged from 3 to 8 weeks from the time of symptom onset. The cough resolved at a later follow-up. In the previously mentioned Italian study [6••], persistent cough was appreciated in $5.4 \%$ of the population. Patterning the previous two studies (Osmanov et al.), persistent cough was documented in 5 of 503 children $(1.0 \%)$ [11••]. A different study found that rhinorrhea was among the most common respiratory symptoms that persisted after acute COVID-19 (52.4\%)
[10••]. Feelings of chest tightness or difficulty breathing have also been reported in children $[11 \bullet \bullet, 21]$.

\section{Gastrointestinal}

Nausea, abdominal pain, and diarrhea have been stated as long COVID symptoms in children. In younger children, abdominal pain can be a presenting feature of COVID-19 in up to $27.7 \%$; however, less than $5 \%$ of children experience this symptom $>4$ weeks $[10 \bullet \bullet, 21]$. Of more concern is a child who had COVID-19 and three to six weeks later presents with an acute abdominal picture combined with high fever, rash, and conjunctival injection. This clinical presentation is more concerning for multisystem inflammatory syndrome in children (MIS-C) or also referred to as pediatric multi-system inflammatory syndrome temporally related to SARS CoV-2 (PIMS-TS). A summary of the findings discussed in this review is summarized in Fig. 2.

\section{Predictors for Long COVID}

A study analyzing 4182 adult cases of COVID-19 reported 558 (13.3\%) participants with symptoms lasting $\geq 28$ days [23]. The authors created a model that could discriminate which adults were more likely to have long COVID. Sudre et al. concluded that the number of symptoms in the first week combined with age and sex reached an area under the curve for predicting long COVID of 76.7\%. Comparable studies in children may lead to the creation of models that could help clinicians track symptoms, and more importantly test interventions that may reduce symptom burden. At present, pathophysiologic reasons that may explain why some children are more susceptible to long COVID are unknown.

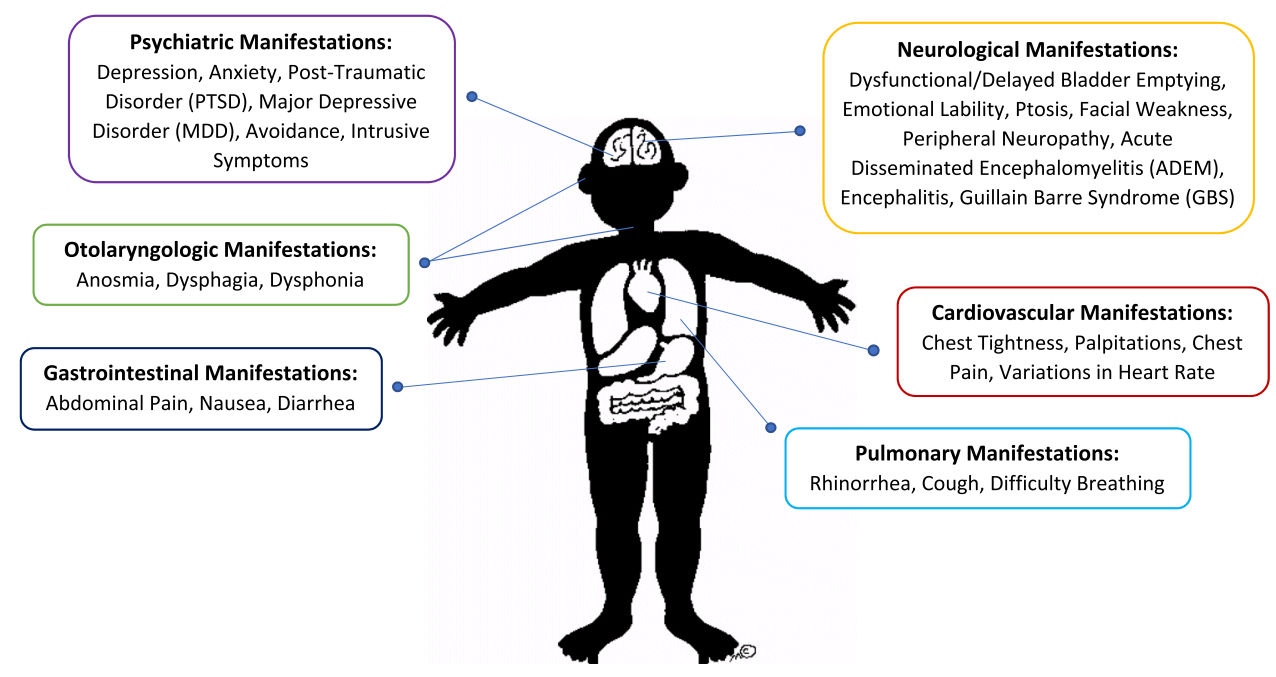




\section{Pathophysiologic Proposals Related to SARS-CoV-2 Manifestations}

Below is a synopsis of SARS-CoV-2 interactions according to different organ systems.

- Brain: SARS-CoV-2 typically gains entry into the central nervous system via hematogenous spread, stimulating neuroinflammation, and triggers a coagulative cascade; alteration to neurotransmitters, NMDA receptors, and glutamate result in neuronal damage and neurologic symptoms [24].

- Otolaryngologic: sustentacular cells line the olfactory neuroepithelium and abundantly express ACE2 receptors (receptor for SARS-CoV2 virus) [25]; depletion of hair cells and supporting cells of the organ of Corti have been associated with hearing loss [26].

- Lungs: virus injures type I and II pneumocytes, and breaks both the lung epithelial barrier and underlying vascular endothelium, leading to an influx of proteinaceous material, fluid, and surfactant dysfunction with overall reduction in gas exchange [27].

- GI: effector $\mathrm{CD}^{+}{ }^{+} \mathrm{T}$ cells migrate to the small intestine via the gut-lung axis followed by stimulation of Th17 cells and neutrophils causing intestinal immune damage [28].

- Heart: systemic inflammation releases high levels of cytokines that are known to injure myocytes and the vascular endothelium [29••].

\section{Multisystem Inflammatory Syndrome in Children (MIS-C)}

Amidst the current COVID-19 pandemic, a novel syndrome affecting children and adolescents rose to great attention across the globe in the latter half of April 2020 [30, 31, 32]. Although MIS-C does not fit the definition of long COVID, many of the sequelae from this devastating disease can result in long-term childhood symptoms/ complications. According to the Center for Disease Control and Prevention, MIS-C is defined by (1) an individual aged less than 21 years old; with (2) clinical criteria of a minimum of 24-h history of subjective or objective fever $\geq 38.0{ }^{\circ} \mathrm{C}$, severe illness necessitating hospitalization, and involvement of two or more organ systems; (3) laboratory evidence of inflammation; (4) laboratory or epidemiologic evidence of SARS-CoV-2 infection; and (5) no alternative diagnosis. The signs and symptoms of MIS-C include fever, abdominal pain, vomiting, diarrhea, skin rash, mucocutaneous lesions, hypotension, and cardiovascular and neurologic compromise [33]. Reviews of complications secondary to MIS-C have been described elsewhere [34, 35].

\section{Conclusion}

Although the manifestations of long COVID are new in the field of pediatrics, evidence suggests that the symptoms are variable and can span across multiple organ systems. During the initial stages of the pandemic, the pediatric population was often overlooked as they had less rates of infection and poor outcomes were rare. This new wave of COVID-19 is resulting in a rise of cases in the unvaccinated pediatric populations and may provide more data and insight into the long-term effects of COVID-19 in children and adolescents. Time will provide an advanced understanding for the prevention and appropriate care of long COVID in the pediatric population.

Acknowledgements The authors wish to thank Dr. Matilde Ruiz Garcia for reviewing their manuscript.

\section{Declarations}

Conflict of Interest The authors declare no competing interests.

\section{References}

Papers of particular interest, published recently, have been highlighted as:

- Of importance

- Of major importance

1. Aleksova A, Gagno G, Sinagra G, et al. Effects of SARS-CoV-2 on cardiovascular system: the dual role of angiotensin-converting enzyme 2 (ACE2) as the virus receptor and homeostasis regulator-review. Int J Mol Sci. 2021;22(9):4526. https://doi.org/ 10.3390/ijms22094526.

2. Borrelli M, Corcione A, Castellano F, Fiori Nastro F, Santamaria F. Coronavirus disease 2019 in children. Front Pediatr. 2021;9: 668484. https://doi.org/10.3389/fped.2021.668484.

3. Thomson H. Children with long covid. New Sci 1971. 2021;249(3323):10-1. https://doi.org/10.1016/S0262-4079(21) 00303-1.

4. CDC. COVID-19 and your health. Centers for Disease Control and Prevention. Published February 11, 2020. Accessed August 1, 2021. https://www.cdc.gov/coronavirus/2019-ncov/long-termeffects.html.

5. Lopez-Leon S, Wegman-Ostrosky T, Perelman C, et al. More than 50 long-term effects of COVID-19: a systematic review and meta-analysis. Sci Rep. 2021;11(1):16144. https://doi.org/ 10.1038/s41598-021-95565-8.

6.• Buonsenso D, Munblit D, Rose CD, et al. Preliminary evidence on long COVID in children. medRxiv. 2021:2021.01.23.21250375. 
https://doi.org/10.1101/2021.01.23.21250375. One of the first to show data on pediatric long COVID.

7. Galindo R, Chow H, Rongkavilit C. COVID-19 in children. Clinical manifestations and pharmacologic interventions including vaccine trials. Pediatr Clin N Am. 2021;68:961-76. https://doi.org/10. 1016/j.pcl.2021.05.004.

8.• Castagnoli R, Votto M, Licari A, et al. Severe acute respiratory syndrome coronavirus 2 (SARS-CoV-2) infection in children and adolescents: a systematic review. JAMA Pediatrics. 2020. E1-E8. Among the first systematic reviews describing COVID-19 in children.

9. Hoang A, Chorath K, Moreira A, et al. COVID-19 in 7780 pediatric patients: a systematic review.EClinicalMedicine. 2020. https:// doi.org/10.1016/j.eclinm.2020.100433.

10.• Molteni E, Sudre CH, Canas LS, Bhopal SS, Hughes RC, Antonelli $\mathrm{M}$, et al. Illness duration and symptom profile in symptomatic UK school-aged children tested for SARS-CoV-2. Lancet Child Adolesc Health. 2021. A large-scale study on long COVID in children and adolescence.

11.•• Osmanov IM, Spiridonova E, Bobkova P, Gamirova A, Shikhaleva A, Andreeva M, et al. Risk factors for long covid in previously hospitalised children using the ISARIC Global follow-up protocol: a prospective cohort study. Eur Respir J. 2021;2101341. This is one of the largest pediatric prospective cohort studies to assess symptoms of long COVID in children and adolescence.

12. Zhang H, Xu H, Huang L, Wang Y, Deng F, Wang X, et al. Increased occurrence of PTSD symptoms in adolescents with major depressive disorder soon after the start of the COVID-19 outbreak in China: a cross-sectional survey. BMC Psychiatry. 2021;21(1):395.

13. Racine N, McArthur BA, Cooke JE, Eirich R, Zhu J, Madigan S. Global prevalence of depressive and anxiety symptoms in children and adolescents during COVID-19: a meta-analysis. JAMA Pediatr. 2021.

14. Danese A, Smith P, Chitsabesan P, Dubicka B. Child and adolescent mental health amidst emergencies and disasters. Br J Psychiatry J Ment Sci. 2020;216(3):159-62.

15. Lechien JR, Chiesa-Estomba CM, Beckers E, Mustin V, Ducarme $\mathrm{M}$, Journe F, et al. Prevalence and 6-month recovery of olfactory dysfunction: a multicentre study of 1363 COVID-19 patients. J Intern Med. 2021;290(2):451-61.

16. Renaud M, Thibault C, Le Normand F, Mcdonald EG, Gallix B, Debry C, et al. Clinical outcomes for patients with anosmia 1 year after COVID-19 diagnosis. JAMA Netw Open. 2021;4(6):e2115352.

17. Halfpenny R, Stewart A, Carter A, Wyatt M, Jephson C, O'Dwyer $\mathrm{E}$, et al. Dysphonia and dysphagia consequences of paediatric inflammatory multisystem syndrome temporally associated with SARS-CoV-2 (PIMS-TS). Int J Pediatr Otorhinolaryngol. 2021;148:110823.

18. Lindan CE, Mankad K, Ram D, et al. Neuroimaging manifestations in children with SARS-CoV-2 infection: a multinational, multicentre collaborative study. Lancet Child Adolesc Health. 2021;5(3):167-77. https://doi.org/10.1016/S2352-4642(20) 30362-X. A paper outlining the neurologic complications of long COVID.

19. Singer TG, Evankovich KD, Fisher K, Demmler-Harrison GJ, Risen SR. Coronavirus infections in the nervous system of children: a scoping review making the case for long-term neurodevelopmental surveillance. Pediatr Neurol. 2021;117:47-63. https:// doi.org/10.1016/j.pediatrneurol.2021.01.007.

20. Frank CHM, Almeida TVR, Marques EA, de Sousa Monteiro Q, Feitoza PVS, Borba MGS, et al. Guillain-Barré Syndrome associated with SARS-CoV-2 infection in a pediatric patient. J Trop Pediatr. 2021;67(3). https://doi.org/10.1093/tropej/fmaa044.
21. Radtke T, Ulyte A, Puhan MA, Kriemler S. Long-term symptoms after SARS-CoV-2 infection in children and adolescents. JAMA. 2021. Longitudinal study on long COVID in children and adolescence.

22. Ludvigsson JF. Case report and systematic review suggest that children may experience similar long-term effects to adults after clinical COVID-19. Acta Paediatr Oslo Nor 1992 [Internet]. 2020 Dec 3 [cited 2021 May 22]; Available from: https://www.ncbi.nlm. nih.gov/pmc/articles/PMC7753397.

23. Sudre $\mathrm{CH}$, Murray B, Varsavsky $\mathrm{T}$, et al. Attributes and predictors of long COVID [published correction appears in Nat Med. 2021 Jun;27(6):1116]. Nat Med. 2021;27(4):626-31. https://doi.org/10. 1038/s41591-021-01292-y.

24. Boldrini M, Canoll PD, Klein RS. How COVID-19 affects the brain. JAMA Psychiat. 2021;78(6):682-3. https://doi.org/10.1001/ jamapsychiatry.2021.0500.

25. Butowt R, von Bartheld CS. Anosmia in COVID-19: underlying mechanisms and assessment of an olfactory route to brain infection. Neuroscientist. 2021;27(6):582-603. https://doi.org/10.1177/ 1073858420956905 .

26. Merchant SN, Adams JC, Nadol JB Jr. Pathology and pathophysiology of idiopathic sudden sensorineural hearing loss. Otol Neurotol. 2005;26(2):151-60. https://doi.org/10.1097/00129492-20050 3000-00004.

27. Oliveira TL, Melo IS, Cardoso-Sousa L, et al. Pathophysiology of SARS-CoV-2 in lung of diabetic patients. Front Physiol. 2020;11:587013. https://doi.org/10.3389/fphys.2020.587013.

28. Ye Q, Wang B, Zhang T, Xu J, Shang S. The mechanism and treatment of gastrointestinal symptoms in patients with COVID-19. Am J Physiol Gastrointest Liver Physiol. 2020;319(2):G245-52. https://doi.org/10.1152/ajpgi.00148.2020.

29. Basu-Ray I, Almaddah NK, Adeboye A, Soos MP. Cardiac manifestations of coronavirus (COVID-19). In: StatPearls. Treasure Island (FL): StatPearls Publishing; 2021.

30.• Riphagen S, Gomez X, Gonzalez-Martinez C, Wilkinson N, Theocharis P. Hyperinflammatory shock in children during COVID-19 pandemic. Lancet. 2020;395(10237):1607-8. https://doi.org/10. 1016/S0140-6736(20)31094-1. First paper to describe MIS-C.

31. Jiang L, Tang K, Levin M, et al. COVID-19 and multisystem inflammatory syndrome in children and adolescents. Lancet Infect Dis. 2020;20(11):e276-88. https://doi.org/10.1016/S14733099(20)30651-4.

32. Cheung EW, Zachariah P, Gorelik M, Boneparth A, Kernie SG, Orange JS, et al.Multisystem inflammatory syndrome related to COVID-19 in previously healthy children and adolescents in New York City. JAMA [Internet]. 2020 Jun 8 [cited 2021 May 22]; Available from: https://www.ncbi.nlm.nih.gov/pmc/articles/ PMC7281352.

33. Feldstein LR, Rose EB, Horwitz SM, et al. Multisystem inflammatory syndrome in U.S. children and adolescents. N Engl J Med. 2020;383(4):334-46. https://doi.org/10.1056/NEJMoa2021680.

34. Feldstein LR, Tenforde MW, Friedman KG, Newhams M, Rose EB, Dapul H, et al. Characteristics and outcomes of US children and adolescents with multisystem inflammatory syndrome in children (MIS-C) compared with severe acute COVID-19. JAMA. 2021;325(11):1074-87.

35. Godfred-Cato S, Tsang CA, Giovanni J, Abrams J, Oster ME, Lee $\mathrm{EH}$, et al. Multisystem inflammatory syndrome in infants $<12$ months of age, United States, May 2020-January 2021. Pediatr Infect Dis J. 2021;40(7):601-5.

Publisher's Note Springer Nature remains neutral with regard to jurisdictional claims in published maps and institutional affiliations. 